\title{
Phantom trips: Overestimating the traffic impacts of new development
}

\author{
Adam Millard-Ball ${ }^{a}$ \\ University of California, Santa Cruz
}

\begin{abstract}
The Trip Generation Manual is the standard reference for assessing the impacts of new development on traffic congestion and the environment in the United States. However, a comparison to household surveys suggests that the Trip Generation Manual overestimates trips by 55 percent-likely because its data represent a biased sample of development in the U.S. Moreover, the data in the Trip Generation Manual are ill suited to many analyses of traffic impacts, development impact fees, and greenhouse gas emissions because they do not account for substitution effects. Most trips "generated" by new developments are not new, but instead involve households reshuffling trips from other destinations. These twin problems—theoretical and practical—are likely to lead to the construction of excessive roadway infrastructure and to the overestimation of the congestion, fiscal, and environmental impacts of new development.
\end{abstract}

Data available in supplementary file: https:/www.jtlu.org/index.php/jtlu/rt/suppFiles/384/0.

\section{$1 \quad$ Introduction}

Trip generation analysis is the bread and butter of transportation planning and traffic engineering. By estimating the number of vehicle trips that will be attracted to a proposed development, planners and engineers can analyze a project's impact on traffic congestion, air quality, and global climate change. Vehicle trip generation estimates, coupled with data on existing traffic flows, form the basis for the analysis of future congestion on nearby streets and of environmental impacts throughout the community.

In the United States, the Trip Generation Manual, an informational report by the Institute for Transportation Engineers (ITE 2012), is a key source of data. The heart of the manual reports results from field surveys of 172 distinct land uses on the number of trips generated per square foot of development, per employee, or per other metric. Together with the Trip Generation Handbook (ITE 2004), which provides ITE's accompanying recommended practice, the Trip Generation Manual is the standard reference for developers, municipalities, state highway departments and others who seek to assess the impacts of new development. ${ }^{1}$

ITE emphasizes that its published trip generation rates apply to suburban, automobile-oriented contexts and are not suitable for use in downtowns, mixed-use developments, and other areas with a non-negligible share of trips made by public transit and nonmotorized modes. Indeed, a large literature (reviewed briefly later in this paper) provides guidance on trip generation analysis for these types of de-

${ }^{1}$ In 2012, ITE published the 9th edition of the Trip Generation Manual, which in previous editions was known simply as Trip Generation. The 9th edition of the manual now incorporates the 2nd edition of the Trip Generation Handbook, but the handbook was not updated as part of the incorporation. Thus, in this paper, I refer to the handbook as a separate publication, even though it now forms part of the manual. Note that trip generation data remained unchanged for most land uses between the 8th and 9th editions of the manual; use of the 8th edition rates does not materially alter the results of this paper.

a adammb@ucsc.edu

Copyright 2015 Adam Millard-Ball

http://dx.doi.org/10.5198/jtlu.2015.384

ISSN: 1938-7849 | Licensed under the Creative Commons Attribution - NonCommercial License 3.0.

The Journal of Transport and Land Use is the official journal of the World Society for Transport and Land Use (WSTLUR) and is published and sponsored by the University of Minnesota Center for Transportation Studies. 
velopments. However, there is little work to date that examines the validity of ITE's trip generation rates even when used for their intended purposes - for example, in the context of a typical suburban subdivision or shopping center. The first part of this paper helps to address that void by comparing estimates of total vehicle trips based on ITE rates to those based on household travel surveys.

ITE's Trip Generation Handbook provides step-by-step guidance on the process of estimating numbers of vehicle trips and offers limited suggestions on how to account for trip chaining and other special circumstances. However, the contexts in which ITE rates are employed-ranging from intersection to air quality analyses - are far broader than considered by the ITE handbook or most planning or traffic engineering texts. In the second part of the paper, I discuss the extent to which ITE trip generation rates are appropriate for different purposes. In particular, I draw out the importance of distinguishing between the average and marginal number of vehicle trips associated with a development.

The issues discussed in this paper - the accuracy of ITE-based trip generation estimates and the appropriate uses of ITE rates - matter because of how traffic analyses shape urban development patterns and infrastructure investment in U.S. cities. If trip generation estimates are inflated, then catering for "phantom trips" may lead to roads with more and wider lanes and intersections with longer signal phases - and, in turn, to urban places that are hostile to pedestrians and devote too much land to vehicle infrastructure (Millard-Ball and Siegman 2006). Ewing et al. (2011) describe some of the long-run effects of inflated estimates of traffic, notably heightened community concerns about a project's impact, which can result in the project being scaled back. The market demand may then resurface at another location, often at a lower density and with more traffic.

This paper begins with a discussion of standard practice in trip generation analysis and reviews the critiques to date in the academic and professional literature. It then presents the results of a simple accounting check for trip generation-a comparison of total trips estimated from ITE-published rates with those derived from other sources. The first comparison is a cross-sectional analysis using 2009 data, while the second is a longitudinal analysis from 1990 to 2009. The paper then explores potential reasons for the discrepancy. The subsequent section of the paper focuses on the distinction between average and marginal trip generation estimates and how this affects the suitability of ITE-published rates for particular analyses. It concludes with suggestions for alternatives to current standard practice.

\section{The practice of trip generation analysis}

\subsection{The ITE-based method}

At its core, estimating trip generation for site-specific analysis is one of the more straightforward aspects of traffic engineering and transport planning. (In contrast, city- or region-wide analysis usually relies on a more sophisticated modeling approach based on household survey data and is not considered here. ${ }^{2}$ ) First, the analyst must gather data on the land uses to be built and match them to the 172 land-use categories in ITE's Trip Generation Manual. The land uses, which range from a "waterport/marine terminal" to an "automated car wash," can be remarkably specific. A "baby superstore" is distinct from a "toy/children's superstore," and a "city park" is distinct from a "county park." Alternative sources of trip generation data do exist-for example, in San Diego (SANDAG 2002), Vermont (Byrne et al. 2012), San Francisco, and New York City; see also the review by Clifton et al. (2012) — but ITE is the standard reference in the United States. The Trip Generation Manual also enjoys some use internationally.

Second, the time period of interest must be determined, such as the a.m. or p.m. peak hour or the entire day. For traffic impact analysis, the peak hour is usually most important, while for air qual-

\footnotetext{
${ }^{2}$ Interestingly, ITE trip generation rates have received relatively little attention in the literature, perhaps because researchers see the method as too obviously flawed. Instead, most research on trip generation rates has focused on the process within four-step travel demand models (e.g., Walters et al. 2000). The same is true of many traffic engineering textbooks, which devote little or no space to trip generation analysis derived from ITE rates. See, for example, Mannering et al. (2004).
} 
ity purposes the entire day is relevant. Determining the base number of trips is then a matter of simple multiplication of the size of the development by the relevant trip generation rate for that particular land use. (The estimate is actually of vehicle trip ends, but for brevity I use the term "trip" throughout this paper.) For example, the Trip Generation Manual gives the weekday rate for a 24-hour convenience market as 737.99 per 1000 square feet, so a 10,000-square-foot store would be expected to generate 7380 trips on an average weekday. For some land uses, formulae are also given that express trip generation as a logarithmic or other nonlinear function of the quantity of land use.

Refinements to this basic procedure are suggested in ITE's (2004) Trip Generation Handbook. In particular, "pass-by" and "diverted linked" trips can be accounted for, recognizing that some motorists would have been driving past or close to the destination anyway, en route to another destination. Pass-by and diverted linked trips are considered in more detail later in this paper. Other refinements discussed in the handbook include accounting for features of a development that are likely to reduce vehicle trips, such as mixed uses, and transportation demand management programs.

The Trip Generation Manual is primarily a source of data, and the applications to which that data are put are clearly outside the control of ITE. However, three purposes are particularly common. The first, traffic impact analysis for new development projects or rezoning, uses trip generation estimates in conjunction with counts of existing traffic to assess changes in congestion at specific intersections and roadway links.

The second application, impact fee assessment, charges developers for the cost of upgrading local and regional road infrastructure. The fee may be tied to the traffic impact analysis or simply be a flat rate based on the estimated number of trips generated. For example, the Washington State Department of Transportation (WSDOT) has a flat fee of \$36 per average daily trip for smaller projects in Snohomish County; for larger developments, WSDOT uses the traffic study (which is based on trip generation estimates) to charge a share of the cost of various highway widening and other capacity-increasing projects. ${ }^{3}$

The third application, environmental review, uses trip generation figures as an input for modeling the impacts of new development on air quality and greenhouse gas emissions. For example, in California, one commonly used model is URBEMIS, which uses ITE trip generation rates as a key input to estimate the air quality and $\mathrm{CO}_{2}$ impacts of new development. A review of environmental impact analyses by the California Air Pollution Control Officers Association (CAPCOA 2008, p. 59) found that URBEMIS is probably "the most consistently used model to estimate a project's direct GHG emissions." Subsequent CAPCOA guidance suggests percentage reductions for transit, travel demand management, and other policies to apply to the ITE trip generation baseline (CAPCOA 2010). Meanwhile, regulatory agencies in states such as California, Washington, and New York recommend the use of URBEMIS or similar tools that are based on ITE rates to quantify greenhouse gas emissions. ${ }^{4}$

In summary, with all three purposes - traffic impact analysis, impact fee assessment, and environmental review - there is a direct relationship between the data in the Trip Generation Manual and analyses of future congestion, assessment of developer fees, and studies of environmental impacts.

\subsection{Concerns with trip generation analysis}

The most common criticisms of the data in the Trip Generation Manual and ITE's associated recommended practice relate to how they reinforce the automobile-oriented nature of urban development.

\footnotetext{
${ }^{3}$ See http://www.wsdot.wa.gov/Northwest/DevelopmentServices/PrivateDevelopment.htm

${ }^{4}$ Examples include the Bay Area Air Quality Management District's May 2011 Air Quality Guidelines, which recommend the use of URBEMIS; New York State Department of Environmental Conservation Guide for Assessing Energy Use and Greenhouse Gas Emissions in an Environmental Impact Statement, which recommends the use of ITE rates coupled with assumptions on trip length and appropriate emission factors; and Washington State Department of Ecology's June 2011 guidance, Including Greenhouse Gas Emissions in SEPA Reviews, which suggests several technical tools based on ITE rates, including URBEMIS, a spreadsheet by a consulting firm, and the CalEEMod model.
} 
The manual explicitly states that it focuses on reporting trip generation at suburban land uses with little or no transit. Shoup (2003) argues that a circular logic contributes to increased traffic and sprawl; if trip (and parking) generation rates derived from sprawling areas are used to design infrastructure for new development, then more sprawl will result. The circle is completed when these new, car-oriented developments are in turn surveyed to update trip generation rates.

The limited applicability of ITE-published rates to mixed-use, high-density centers has long been recognized, and ITE's publications themselves have extensive caveats to this effect. However, practices have evolved to allow developers to adjust down their trip generation rates in certain contexts (Ewing et al. 2011; Millard-Ball and Siegman 2006; Cervero and Arrington 2008; Lee et al. 2011; Clifton et al. 2012; Bochner et al. 2011; Handy et al. 2013). ${ }^{5}$ Thus, data and practice now at least partially address the special circumstances of mixed-use and transit-oriented development. Locally collected data have also been employed in other contexts where ITE-published rates may not be appropriate, such as the primarily rural and small-urban state of Vermont (Byrne et al. 2012).

Other concerns include the misplaced precision with which trip generation data are reported (Shoup 2003), the use of just a single variable such as floor area to estimate trips (Shoup 2003), and the implausibility of data when the two ITE informational reports, Parking Generation and Trip Generation, are considered together (Shoup 1999). Planners and engineers have also noted discrepancies between trip generation estimates derived from household surveys and those from ITE rates or other driveway counts (FHWA 1985; Reid 1982). In the Australian context, Barnard and Brindle (1987) highlight inconsistent estimates produced by standard trip generation analyses and call instead for engineers to turn to individual-level models - or at least to employ additional sources of data such as household surveys.

With the partial exception of Reid (1982), who compares ITE residential trip generation rates to those derived from household surveys in Southern California, previous critiques of trip generation analysis have focused on a limited dimension of the issue. Most often, researchers seek to improve trip generation estimates for mixed-use or transit-oriented developments, or otherwise use additional data to improve the accuracy of estimates. The underlying philosophy of trip generation analysis has been accepted. In the remainder of this paper, I examine the validity of ITE's data and recommended approach in a broader context.

\section{A simple accounting check for trip generation}

The validity of the rates presented in the Trip Generation Manual can be assessed, at least to a first approximation, by summing the number of trips that would be expected from each land-use category and comparing the total to an alternative data source on total trip making, such as a household survey. This is most easily accomplished for the entire United States, but a similar exercise can be done for other geographic entities. I primarily focus on a cross-sectional comparison for 2009 (the most recent National Household Travel Survey), but I also include a longitudinal comparison from 1990 to 2009. The spreadsheet model is provided on this journal's website ${ }^{6}$, allowing readers to examine the detailed results and substitute their own assumptions.

\subsection{Data sources}

Two pieces of data are critical to the analysis here: an estimate of total land use and an estimate of trips matched to each land-use type. For residential land uses, I use data on housing unit numbers from the 2009 American Community Survey one-year estimates. For commercial land uses, I use square footage

\footnotetext{
${ }^{5}$ See also the US EPA spreadsheet tool based on Ewing et al. (2011), available at www.epa.gov/dced/mxd_tripgeneration.html ${ }^{6}$ See https://www.jtlu.org/index.php/jtlu/editor/downloadFile/384/3291
} 
estimates from the 2003 Commercial Buildings Energy Consumption Survey (CBECS), published by the Energy Information Administration, and scale the 2003 estimates to 2009 levels. The CBECS is based on a sample of 5215 buildings in the United States and includes office, retail, medical, and other types of commercial establishments. Note that the CBECS excludes buildings under 1000 square feet and mixed-use buildings where commercial uses account for less than half of the floor space. These exclusions will bias the ITE-based estimates slightly downwards.

Industrial and agricultural uses are not covered by the CBECS, and I exclude them from the analysis due to lack of square footage data. I include the data for both vacant and occupied buildings, as most buildings will experience some vacancies over the course of their life span. However, I also report results based on data for occupied buildings only.

Data on the number of trips come from the 2009 National Household Travel Survey (NHTS) (FHWA 2011a). The standard NHTS trip weights are used, which means that the weighted sum of trips should match the total number of household trips in the United States in 2009. Only trips made by car, van, SUV, pickup truck, other truck, and RV where the respondent is the driver, plus trips made by taxi, are considered, in order to obtain an estimate of vehicle rather than person trips. Note that the definition of a "trip" in NHTS matches the ITE usage-each element of a tour (e.g., home to daycare to office to grocery store to home) is counted as a separate trip. As I count each trip twice, once based on the origin and once based on the destination, each data point indicates a trip end.

The NHTS data give a total of 468 billion trip ends in the United States in 2009, or 2269 billion vehicle miles traveled (VMT) when multiplied by the weighted average reported trip length of 9.7 miles. For comparison, the Federal Highway Administration (FHWA) reports a slightly higher total of 2633 billion miles driven by light-duty vehicles in 2009; these data come largely from traffic counters (FHWA 2011b). ${ }^{7}$ The difference suggests that 13.8 percent of VMT is underreported in the NHTS, is for longdistance trips that are not captured by the NHTS, or is not for household travel (e.g., by government vehicles, cruising taxis, or commercial vans). To account for this discrepancy, I increase NHTS trip estimates by an adjustment factor of $1 / 0.862$. Note that underreporting is only one potential reason for the difference between the FHWA and NHTS estimates.

Underreporting is an issue with any household travel survey (see, for example, Wolf et al. 2003), and the NHTS is no exception. Studies comparing self-reported trips from NHTS-style surveys and GPS devices have found that between 10 percent and 35 percent $^{8}$ of GPS-identified trips go unreported in surveys (Bricka and Bhat 2006). Not all of the discrepancy is due to survey errors, as some GPS-based methods may be overly sensitive-for example, picking up the walk from an off-site parking lot to the destination as a separate trip or assuming that a long dwell at a traffic signal denotes a gap between two separate trips (Bricka et al. 2012). Moreover, some of the underreporting concerns trips by nonmotorized modes, which are particularly difficult to capture in surveys but are not relevant to the analysis here. Based on the comparison with FHWA data, it appears that trip underreporting is less of a problem with the NHTS than with other household travel surveys and that the 13.8 percent adjustment is reasonable. The apparent superior performance of the NHTS may be due to an interview design with multiple prompts for additional trips, a one-day sample period that improves recall, imputation of missing trips, and/or the weighting process within the NHTS. ${ }^{9}$

\footnotetext{
${ }^{7}$ The counts reported in the Trip Generation Manual are not limited to light-duty vehicles. However, for the commercial and residential land uses analyzed here, almost all trips are likely to be accounted for by light-duty vehicles. Note that the FHWA estimates include VMT on local streets as well as highway travel, and so there is no issue of particular types of streets being excluded from the FHWA totals.

${ }^{8}$ This range excludes one outlier (81 percent). In that case, however, the count of GPS trips includes commercial trips, vehicle usage by non-household members, and other types of trips that were not designed to be captured by the telephone survey (Bricka and Bhat 2006).

${ }^{9}$ Indeed, methodological and definitional changes were made starting with the 2001 NHTS to address previous criticisms that nonmotorized trips were underreported. For example, multiple prompts were added to probe for additional trips. See Pucher et al. (2011).
} 
Key challenges in the analysis lie in matching land-use data to the land-use categories in the Trip Generation Manual and matching NHTS trip data to land-use categories. Table 1 shows the assumptions that were used in matching the data. There are inevitable uncertainties here, not least because trip generation rates vary greatly between ostensibly similar land uses, ${ }^{10}$ and because NHTS asks about trip purpose rather than the land use at the origin and destination. For this reason, aggregated land-use subcategories are used. Even so, the first-level categories (residential and commercial) are likely to be more reliable than the subcategories (e.g., commercial-office and commercial-retail) shown in Table 1.

The choice of the appropriate trip generation rate also requires some judgment. ${ }^{11}$ The rate for the most generic land use (such as "general office building" for office or "shopping center" for retail) is used where possible. Otherwise, a land use with a low trip generation rate is used in order to make the analysis more conservative. For example, for education, I use the "high school" rate, which is lower than the rates for elementary schools, middle/junior high schools, and junior/community colleges. Similarly, for health care, I use the "hospital" rate, which is about half that for clinics and medical-dental office buildings. Readers who wish to substitute their own assumptions can easily do so using the spreadsheet model made available via the journal website.

The confidence intervals and standard errors reported in the analysis account only for sampling error in the NHTS, CBECS, and ITE trip generation rates. Sampling errors from the American Community Survey are ignored, as they are negligible. At the level of the United States, the 95 percent confidence interval for the total number of housing units is \pm 0.1 percent. Even within individual metropolitan areas, the bounds are typically $\pm<1$ percent.

\footnotetext{
${ }^{10}$ For example, ITE (2012) reports the weekday trip generation rate for a Discount Home Furnishing Superstore (code 869) as 20.00 trips per 1000 square feet. For a Furniture Store (code 890), the rate is 5.06 trips per 1000 square feet.

${ }^{11}$ The average rate per residential unit or per 1000 square feet is used. While ITE provides regression equations for some land uses, this would require additional assumptions on the distribution of development sizes. If there are no biases in the ITE dataset, then using the average rate rather than the regression equation will still provide an unbiased estimate of total trips. ITE also provides alternative metrics for some land-use categories, such as trips per employee or seat. However, the alternative metrics are not consistently available across land uses, and again, if there are no biases in the ITE dataset, using the average rate per unit or per 1000 square feet will provide an unbiased estimate of total trips.
} 
Table 1: Matching land-use data, ITE categories, and trip purposes.

\begin{tabular}{|c|c|c|c|}
\hline Land Use & NHTS Trip Purposes* & Land-Use Data Categories & ITE Land-Use Code and Name \\
\hline \multicolumn{4}{|l|}{ Residential } \\
\hline Single-family detached & $\begin{array}{l}\text { For households living in single- } \\
\text { family detached housing: } \\
\text { - Home } \\
\text { - Visit friends/relatives }\end{array}$ & - One unit detached & 210: Single-family detached \\
\hline \multirow{3}{*}{ Other owner-occupied } & \multirow{3}{*}{$\begin{array}{l}\text { For households living in other } \\
\text { owner-occupied housing: } \\
\text { - Home } \\
\text { - Visit friends/relatives }\end{array}$} & $\begin{array}{l}\text { Owner Occupied } \\
\text { - One unit attached } \\
\text { - } 2-50 \text { unit building }\end{array}$ & $\begin{array}{l}\text { 230: Residential condominium/ } \\
\text { townhouse }\end{array}$ \\
\hline & & $\begin{array}{l}\text { Owner Occupied } \\
-51+\text { unit building } \\
\end{array}$ & $\begin{array}{l}\text { 232: High-rise residential condo- } \\
\text { minium/townhouse }\end{array}$ \\
\hline & & - Mobile home & 240: Mobile home park \\
\hline \multirow[t]{2}{*}{ Other rental } & \multirow{2}{*}{$\begin{array}{l}\text { For households living in other } \\
\text { rental housing: } \\
\text { - Home } \\
\text { - Visit friends/relatives }\end{array}$} & $\begin{array}{l}\text { Rental } \\
\text { - One unit attached } \\
\text { - } 2-50 \text { unit building }\end{array}$ & 220: Apartment \\
\hline & & $\begin{array}{l}\text { Rental } \\
\bullet 51+\text { unit building } \\
\end{array}$ & 222: High-rise apartment \\
\hline \multicolumn{4}{|l|}{ Commercial } \\
\hline Education & $\begin{array}{l}\text { - Work** } \\
\text { - School/religious activity } \\
\text { - Go to school as student } \\
\end{array}$ & - Education & 530: High school \\
\hline Retail & $\begin{array}{l}\text { - Work** } \\
\text { - Shopping/errands } \\
\text { - Buy goods } \\
\text { - Buy services } \\
\text { - Buy gas } \\
\text { - Use personal services } \\
\end{array}$ & $\begin{array}{l}\text { - Food sales } \\
\text { - Retail (other than mall) } \\
\text { - Enclosed and strip malls }\end{array}$ & 820: Shopping center \\
\hline Food & $\begin{array}{l}\text { - Work** } \\
\text { - Meals } \\
\text { - Get/eat meal } \\
\text { - Coffee/ice cream/snacks } \\
\end{array}$ & - Food service & 931: Quality restaurant \\
\hline Health Care & $\begin{array}{l}\text { - Work* } \\
\text { - Medical/dental services }\end{array}$ & - Health care & 610: Hospital \\
\hline Office & \begin{tabular}{|l|} 
- Work** \\
- Use professional services: attor- \\
ney/accountant
\end{tabular} & - Office & 710: General office building \\
\hline Religious worship & $\begin{array}{l}\text { - Work** } \\
\text { - Go to religious activity } \\
\text { - Attend funeral/wedding } \\
\end{array}$ & - Religion & 560: Church \\
\hline Other commercial & $\begin{array}{l}\text { - Work* } \\
\text { - Go to library } \\
\text { - Day care } \\
\text { - Social/recreational } \\
\text { - Go to gym/exercise/play sports } \\
\text { - Rest or relaxation/vacation } \\
\text { - Go out/hang out } \\
\text { - Visit public place } \\
\text { - Family personal business } \\
\text { - Pet care } \\
\text { - Attend meeting } \\
\text { - Social event } \\
\text { - Other reason }\end{array}$ & $\begin{array}{l}\text { - Public assembly } \\
\text { - Lodging } \\
\text { - Public order and safety } \\
\text { - Service } \\
\text { - Other }\end{array}$ & 770: Business park \\
\hline
\end{tabular}

* For each trip, NHTS reports the purpose of that trip (i.e., the destination), and the purpose of the previous trip (i.e., the origin). Each are summed separately, so that each trip is associated with two trip ends - and thus the approach matches ITE rates, which also should be interpreted as trip ends. Trips to "transport someone," "pick up someone," "take and wait," and "drop someone off" are allocated proportionately according to the number of trips in each category.

** Work trips are allocated to categories based on proportion of employment in broad categories, based on Bureau of Labor Statistics, May 2009 Occupational Employment and Wage Estimates. 


\subsection{Cross-sectional comparison}

The first method of comparison is cross-sectional, comparing the ITE-based and NHTS-based estimates for a single year (2009). Table 2 shows that the ITE-based method produces an estimate that is 55 percent higher than the NHTS-based method. Since the NHTS numbers are adjusted to match national totals published by the FHWA, the NHTS-based method is likely to be more accurate- suggesting that ITE trip generation rates are substantially overestimated. The overestimate is present across all but one of the land-use types and on both weekends and weekdays (disaggregation available in the spreadsheet model on the journal website).

Figure 1 plots the same data as in Table 2 and more clearly shows the uncertainty due to sampling error in the ITE trip generation database, the NHTS, and the CBECS. There is a wide confidence bound, particularly for individual land-use subcategories, which reflects the small sample size of the CBECS and the limited number of trip generation studies that are available for certain land uses through the Trip Generation Manual. However, in almost all cases, the difference between the NHTSand ITE-based estimates is far larger than could be accounted for by sampling error alone.

There are clearly other uncertainties in the analysis in addition to sampling error. However, the use of alternate assumptions would generally either shift trips between land-use categories, leaving the overall ITE-based overestimate unchanged, or increase the discrepancy between the ITE- and NHTS-based analyses. As noted above, conservative assumptions were made when matching land-use data to ITE trip generation rates, so the use of different trip generation rates generally increases the overestimate. For example, using "medical/dental office building" instead of "hospital" for the medical land-use category increases the overestimate for commercial uses from 54 percent to 61 percent. Similarly, using the rate for another type of food outlet in place of "quality restaurant" would increase the overestimate by up to 159 percent. Excluding vacant buildings from the analysis has a small impact; it reduces the overestimate from 56 percent to 50 percent for residential uses and from 54 percent to 48 percent for commercial uses.

Commercial land-use data are only readily available at the national and census region levels. However, housing unit counts from the American Community Survey are available at any disaggregation based on census geography, while NHTS data are available by metropolitan region (core-based statistical area or CBSA). This allows the residential results from Table 2 to be disaggregated by metropolitan region. As shown in Figure 2, the overestimate produced by the ITE-based method is present across almost every region. The confidence intervals for some metropolitan regions are wide, reflecting small NHTS sample sizes, and future work might usefully consider regional travel surveys conducted by metropolitan planning organizations. However, the advantage of the NHTS is that it provides consistency across regions and avoids the possibility that differences in question wording or methodology may cause some of the variation. 
Table 2: ITE-based vs. NHTS-based trip estimates (residential and commercial trips, 2009).

\begin{tabular}{|c|c|c|c|c|}
\hline Land Use & Land-Use Quantity & $\begin{array}{c}\text { Annual Trips (bn) } \\
\text { (ITE-Based) }\end{array}$ & $\begin{array}{c}\text { Annual Trips (bn) } \\
\text { (NHTS-Based) }\end{array}$ & 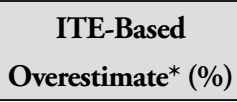 \\
\hline Residential & (million dwelling units) & & & \\
\hline Single-family detached & 73.6 & $\begin{array}{l}253.8 \\
(4.4)\end{array}$ & $\begin{array}{c}170.8 \\
(1.1)\end{array}$ & $49 \%$ \\
\hline Other owner-occupied & 15.8 & $\begin{array}{l}30.1 \\
(1.2)\end{array}$ & $\begin{array}{l}21.9 \\
(0.5)\end{array}$ & $37 \%$ \\
\hline Other rental & 28.7 & $\begin{array}{l}64.2 \\
(2.6)\end{array}$ & $\begin{array}{l}30.9 \\
(0.7)\end{array}$ & $108 \%$ \\
\hline Total Residential & 118.2 & $\begin{array}{r}348.1 \\
(5.3) \\
\end{array}$ & $\begin{array}{l}223.6 \\
(1.1) \\
\end{array}$ & $56 \%$ \\
\hline Commercial & (billion sq. $\mathrm{ft}$.) & & & \\
\hline Education & $\begin{array}{l}11.3 \\
(0.7)\end{array}$ & $\begin{array}{l}41.0 \\
(3.9)\end{array}$ & $\begin{array}{l}13.7 \\
(0.2)\end{array}$ & $198 \%$ \\
\hline Retail & $\begin{array}{l}14.3 \\
(1.0) \\
\end{array}$ & $\begin{array}{l}214.3 \\
(13.0) \\
\end{array}$ & $\begin{array}{l}126.0 \\
(1.0) \\
\end{array}$ & $70 \%$ \\
\hline Food & $\begin{array}{c}1.9 \\
(0.2) \\
\end{array}$ & $\begin{array}{l}60.8 \\
(6.4) \\
\end{array}$ & $\begin{array}{l}42.2 \\
(0.5) \\
\end{array}$ & $44 \%$ \\
\hline Health care & $\begin{array}{l}3.6 \\
(0.3) \\
\end{array}$ & $\begin{array}{l}16.0 \\
(2.6) \\
\end{array}$ & $\begin{array}{l}18.4 \\
(0.3) \\
\end{array}$ & $-13 \%$ \\
\hline Office & $\begin{array}{l}14.0 \\
(0.9) \\
\end{array}$ & $\begin{array}{l}42.0 \\
(3.6) \\
\end{array}$ & $\begin{array}{l}33.1 \\
(0.3) \\
\end{array}$ & $27 \%$ \\
\hline Religious worship & $\begin{array}{c}4.3 \\
(0.3) \\
\end{array}$ & $\begin{array}{l}21.1 \\
(4.3) \\
\end{array}$ & $\begin{array}{c}9.2 \\
(0.3) \\
\end{array}$ & $129 \%$ \\
\hline Other commercial & $\begin{array}{l}18.2 \\
(1.0)\end{array}$ & $\begin{array}{l}61.7 \\
(7.3) \\
\end{array}$ & $\begin{array}{l}54.1 \\
(0.6) \\
\end{array}$ & $14 \%$ \\
\hline Total Commercial & $\begin{array}{l}67.6 \\
(1.9)\end{array}$ & $\begin{array}{l}457.0 \\
(17.8)\end{array}$ & $\begin{array}{l}296.9 \\
(1.3)\end{array}$ & $54 \%$ \\
\hline TOTAL & & $\begin{array}{l}805.1 \\
(18.6)\end{array}$ & $\begin{array}{l}520.5 \\
(1.7)\end{array}$ & $55 \%$ \\
\hline
\end{tabular}

Standard errors in parentheses.

*Compared to NHTS-based estimate. 


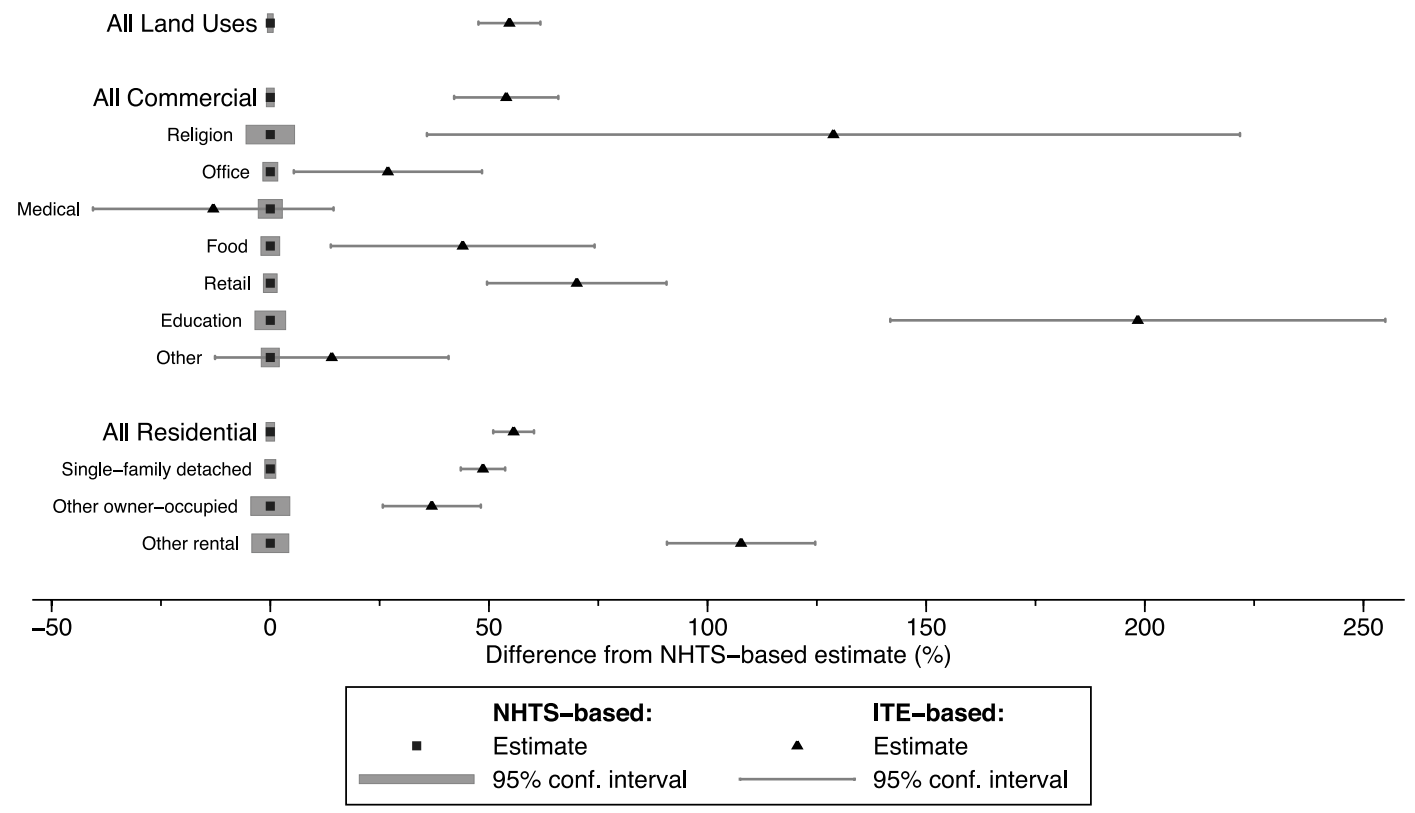

Figure 1: ITE-based vs. NHTS-based trip estimates (residential and commercial trips, 2009).

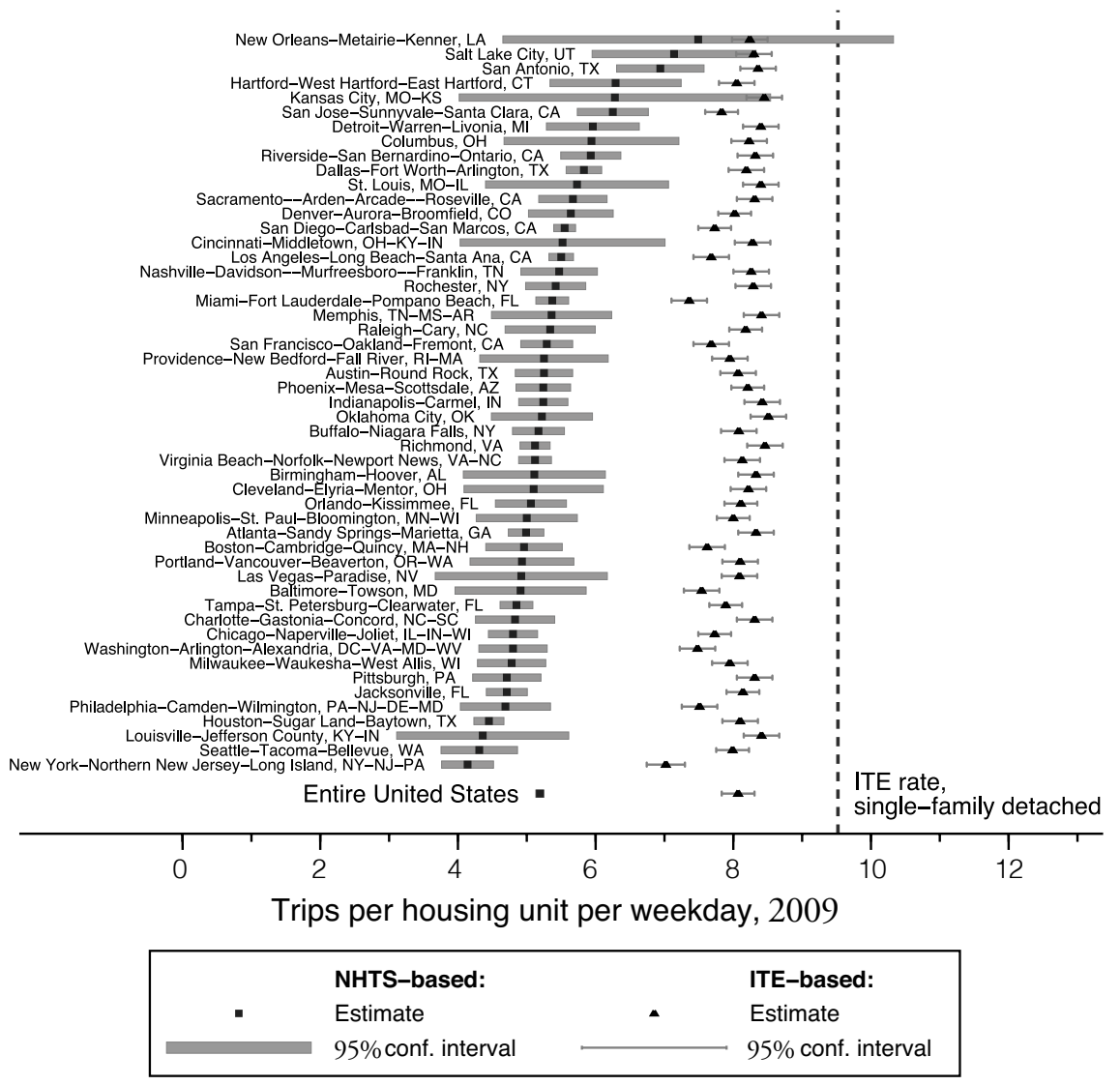

Figure 2: ITE-based vs. NHTS-based trip estimates by metropolitan region (residential trips, 2009).

Notes: NHTS-based estimates include 1/0.862 adjustment factor. ITE-based estimate is a weighted average of trip generation rates for different types of housing, as shown in Table 1. Confidence intervals are based on jackknifed standard errors, using the NHTS-supplied replicate weights; large confidence intervals in some CBSAs are largely due to small sample sizes. 


\subsection{Longitudinal comparison}

A second accounting check comes from comparing changes in trip estimates from the two methodsITE-based and NHTS-based-over time. Here, changes in trip numbers from the four most recent versions of the NHTS $\left(1990,1995,2001\right.$, and 2009) ${ }^{12}$ are compared against the number of new trips that would be expected from net changes in land use over the same period.

The NHTS-based trip estimates are based on the reported results, but then adjust upwards for underreporting and downwards to exclude trips to industrial uses, assuming that this proportion (4 percent) is constant over time. The ITE-based estimates are based on a weighted trip generation rate for residential (7.3 trips per unit per day) and commercial (18.5 trips per 1000 square feet per day), calculated using the data in Table 2 .

As shown in Table 3, there is a large discrepancy between the two sets of estimates, but the sign and size of the discrepancy varies over time. In the 1990-95 period, the higher estimate of change is produced by NHTS. This is a period of slow growth in development (which dampens estimates from the ITE-based method) but substantial rises in population ( 8 percent) and per capita trip making ( 9 percent). The growth in trip making was particularly pronounced because the U.S. emerged from recession over the 1990-95 period. Since 1995, and also over the entire 1990-2009 period, the ITE-based estimates are substantially higher. The greatest discrepancy is from 2001 to 2009, when household trip making was essentially flat but development continued apace.

Table 3: Longitudinal comparison, ITE-based and NHTS-based estimates (residential and commercial trips, 1990-2009).

\begin{tabular}{|l|c|c|c|c|c|}
\hline & NHTS-Based & \multicolumn{3}{|c|}{ ITE-Based } & (bange in \\
\cline { 2 - 5 } & $\begin{array}{c}\text { Change in household } \\
\text { vehicle trip ends } \\
\text { Period }\end{array}$ & $\begin{array}{c}\text { Change in commercial } \\
\text { development } \\
\text { (billion sq. } \mathbf{f t .})\end{array}$ & $\begin{array}{c}\text { Change in residential } \\
\text { units (million) }\end{array}$ & $\begin{array}{c}\text { trip ends } \\
\text { (billion) }\end{array}$ & $\begin{array}{c}\text { ITE-based } \\
\text { overestimate* (\%) }\end{array}$ \\
\hline $1990-1995$ & +79.7 & +1.8 & +5.9 & +27.9 & $-65 \%$ \\
\hline $1995-2001^{* *}$ & +7.3 & +2.9 & +9.7 & +45.4 & $+520 \%$ \\
\hline $2001-2009$ & +1.8 & +8.6 & +12.1 & +90.4 & $+4859 \%$ \\
\hline $\begin{array}{l}\text { Total change: } \\
1990-2009\end{array}$ & +88.9 & +13.2 & +27.7 & +163.7 & $+84 \%$ \\
\hline
\end{tabular}

Sources: NHTS data: FHWA (2011c), with the number of trips reduced by 4 percent to account for industrial uses. The same adjustment factor (1/0.862) as before is used to account for potential underreporting of trips in the NHTS. Commercial land-use data: USDOE (2012), with linear interpolation used to estimate missing years. Warehousing is excluded. Residential land-use data: US Census Bureau Population Estimates Program.

${ }^{*}$ Compared to change in NHTS-based estimate.

**A definitional change in commercial buildings occurred in 2000, with parking garages and commercial buildings on multi-building manufacturing facilities being excluded from 2000 onwards. This will bias downwards the ITE-based estimate for the 1995-2001 period and means that the true overestimate will be greater than indicated.

\section{$4 \quad$ Explaining the discrepancy}

It is clear from both the cross-sectional and longitudinal analyses that there is a severe discrepancy between estimates of total trips based on ITE trip generation rates and those derived from the National Household Travel Survey. The discrepancies hold across almost all land-use categories, both residential and commercial. The overestimate also appears to be increasing over time. According to survey-based estimates, total trip making has been relatively flat since 1995, but using a method based on ITE trip gen-

\footnotetext{
${ }^{12}$ The 1990 and 1995 surveys were named the Nationwide Personal Transportation Survey (NPTS). Earlier versions of the NPTS are not used here because of changes in survey methodology. For 1990, adjusted data are used to ensure comparability with later surveys.
} 
eration rates implies substantial growth in travel as residential and commercial development continues.

The relatively constant discrepancy across different land-use categories (Figure 1 and Table 2) and the lack of a clear pattern across metropolitan areas (Figure 2) or over time (Table 3) make it difficult to pinpoint the main causes of the diverging estimates. Underreporting of trips in the NHTS is unlikely to be a contributor, as I adjust trip counts upwards to account for this possibility. In addition, the discrepancy is consistent across all land-use types, not only those where underreporting tends to be more prevalent, such as short stops at convenience stores as part of a trip chain.

The possibility that trip generation rates have changed over time, meanwhile, is explicitly refuted by ITE in the Trip Generation Manual. ${ }^{13}$ In the past, increases in trip making due to higher incomes, population growth, and highway infrastructure expansion may have roughly matched the increases in building square footage, leaving trip generation rates constant. In the current environment where vehicle travel has plateaued, however, there is a logical contradiction: trip generation rates cannot remain unchanged if development continues while the total number of trips is the same.

Lower trip generation rates from mixed-use and transit-oriented development provide one possible explanation and certainly contribute to the overestimate of the ITE-based method. To assess the importance of this explanation, one can examine how the overestimate correlates with metropolitanlevel patterns of sprawl, vehicle ownership, and mode choice. While the impact of transit-oriented and mixed-use development on trip making occurs at the site level, these impacts should scale up to the metropolitan scale in proportion to the relative importance of these development types.

If non-automobile-oriented development were the primary problem with ITE's rates, one would expect the ITE-based method to be more accurate in sprawling regions with little transit use and high vehicle ownership. The size of the ITE-based overestimate should increase in tandem with residential density, transit use, and walking and decrease with sprawl and vehicle ownership.

As shown in Figure 3, there is either no relationship between the overprediction and these four variables, or else the relationship runs in the opposite direction than expected. Bivariate correlations are either the "wrong" sign or statistically indistinguishable from zero. This conclusion is consistent with results from Muldoon and Bloomberg (2008), who find that ITE trip generation rates overpredict in urban fringe, small town, and rural locations but actually underpredict in urban locations. One possibility is that higher land values in denser urban areas encourage more intensive land use, resulting in more trips (by all modes) per square foot of development.

Such an aggregate analysis does not contradict the findings of site-level studies that do find that certain development types are associated with reduced trip making. However, it does suggest that transit-oriented or mixed-use development, while undoubtedly contributing to ITE's high trip-generation predictions, is not the primary reason for the discrepancy.

${ }^{13}$ The exceptions are "drive-in bank" and "walk-in bank," where ITE notes that trip generation rates have substantially changed in recent years due to technological advances in the banking industry. 

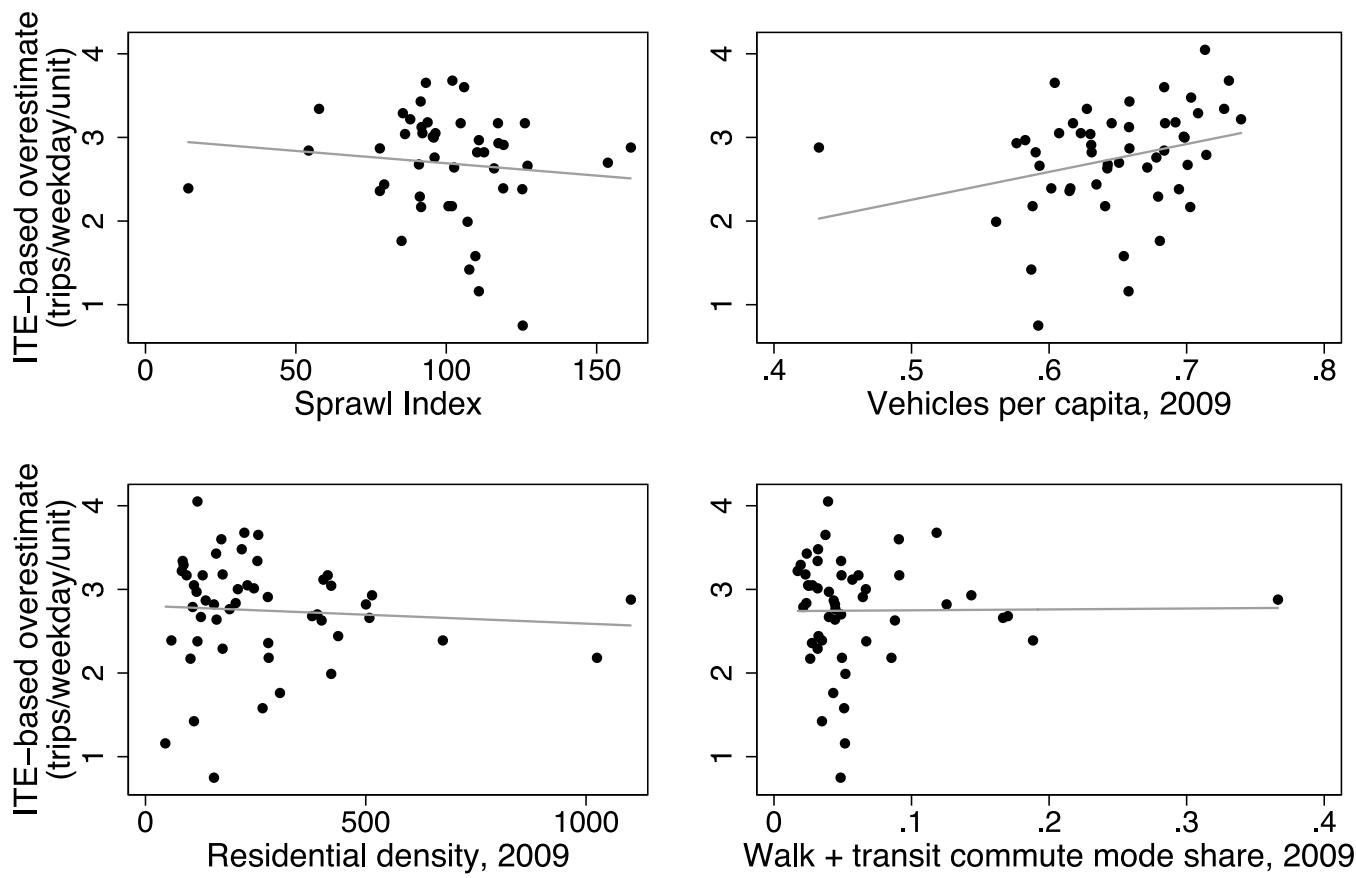

- Actual Fitted

Figure 3: Overestimate of ITE-based method vs. indicators of sprawl by CBSA (residential trips, 2009).

The data points represent the 51 core-based statistical areas (metropolitan regions) that are disaggregated by the NHTS. The ITE-based overestimate is calculated as the difference between the ITE- and NHTS-based estimates for residential trips in each CBSA. Sources: Vehicles per capita, residential density (persons $/ \mathrm{km}^{2}$ ) and commute mode share data from 2009 American Community Survey. Sprawl Index from Ewing et al. (2002); higher values indicate more sprawl. Note that due to changes in metropolitan region definitions, the matching of the Ewing et al. index (which is based on 1990 metropolitan statistical areas) to CBSAs is sometimes imprecise and may not reflect the current extent of the CBSA.

A more compelling possibility is that ITE's trip generation rates are not representative of the building stock or even of new development projects. Unfortunately, the Trip Generation Manual says almost nothing about the characteristics of the developments surveyed beyond their size, and ITE refuses to release further information, citing confidentiality constraints (see Shoup (1999) for similar complaints in the context of ITE's Parking Generation).

The ITE data-collection process, however, is compiled mostly from voluntary submissions of traffic counts from specific developments. Such traffic counts are not conducted as a matter of course; some (non-random) reason must exist to collect the data. Perhaps a particular development was new, and follow-up traffic studies were required to adjust signal timing. Perhaps a large and controversial development required a traffic monitoring plan as a condition of approval. Perhaps the data were required to inform traffic analysis for a similar proposed development - again, meaning that the project is likely to be unusual in some respect, perhaps because of high expected traffic volumes. Or perhaps trip generation studies tend to be commissioned by cities or states in which traffic is a particular concern. While these explanations remain somewhat speculative given the lack of information provided by ITE, it is nonetheless doubtful that data published in the Trip Generation Manual even approximate a random sample of new development. More likely, ITE's data are biased toward more traffic-intensive sites.

ITE's guidance on selecting sites for trip generation studies reinforces the idea that the data are 
biased. The Trip Generation Handbook (ITE 2004, p. 17) recommends that developments where traffic counts are conducted should have "reasonably full occupancy (i.e., at least 85 percent) and appear to be economically healthy." A site should also be "mature (i.e., at least two years old) and located in a mature area so it represents the ultimate characteristics of a 'successful' development." ${ }^{14}$ Using only data from well-patronized, successful developments to forecast the impacts of all new developments will naturally inflate trip-generation rates. While developers presumably do not intend to build unsuccessful projects with high vacancy rates and few customers, inevitably, not every development succeeds.

\section{$5 \quad$ Trip generation: by development or people?}

A more fundamental reason for the overestimate of the ITE-based method of trip generation is its core premise that new development always generates new trips. Neither the ITE publications nor traffic engineering texts are explicit about how this "generation" actually comes about. However, the implicit assumption is that new destination opportunities spur households to make new trips in addition to the trips they are already making, rather than substituting for existing travel.

In practice, however, new development has complex effects on total trip making. Some trips will be completely new, as households take advantage of new employment or recreational opportunities. But most trips substitute for existing ones. They are diverted from existing locations, as people change where they live, work, and shop in light of new possible travel choices, particularly in a context of diminishing marginal utility to new destinations (Metz 2010). In other words, ITE's data are properly interpreted as the average trip generation rate, not the marginal trip generation rate. The average rate is simply the number of trips that could be expected at a development of a particular type. The marginal rate is the number of new trips that could be expected. The marginal rate will typically be less than the average rate, as it accounts for substituted trips. But it is the marginal rate that is almost always the quantity of interest to traffic engineers, planners, and policymakers, who wish to know the net impact of a new development on traffic or greenhouse gas emissions.

Another way of putting this is that new land uses do not generate trips-people do. More precisely, people generate trips as a response to a long list of demographic, economic, and physical variables. The square footage of new development and number of residential units would presumably rank quite far down this list of variables in order of importance.

Scale matters in this analysis. At the micro level of the newly constructed driveway or street that serves a new development, the trips are clearly additional to what would have been there otherwise. The average rate will equal the marginal rate, and so the distinction is of little importance. When trips on arterials and regional-serving freeways are considered, the substitution component becomes more important, and the marginal rate will be less than the average rate. The larger the area of analysis, the greater the likelihood that the previous origin or destination choice (the aging grocery store that has been replaced by a new supercenter as a household's preferred place to shop, for example) lies within that area of analysis, and the more the marginal rate will diverge from the average rate.

Moreover, the difference between the marginal and the average rate will interact with scale in a way that varies by the type of land use. Presumably a new elementary school will not increase the total demand for trips to school any more than a new funeral home will increase the total demand for trips to pay one's respects to the dead. But the situation is less obvious for other land uses. Is a new gasoline service station likely to increase the total demand for gasoline or the number of trips to fuel up? That seems unlikely, except at the most local level when analyzing turn movements at particular intersections. Might

\footnotetext{
${ }^{14}$ The same biases towards economically successful developments are also evident in some studies of trip generation at mixeduse and transit-oriented development. The recommended criteria for data-collection sites in Bochner et al. (2011, p. 4) include that the development "be economically successful (by appearance) and mature (fully occupied for at least a year and in an area that is mostly developed)."
} 
a new movie theater increase total trip making? Quite possibly, if some people would have otherwise stayed at home and watched television. What about new residential development? This is also unclear. New housing units might increase vacancy rates and reduce prices or rents in the existing stock. The price effect might promote smaller households (e.g., young adults can afford to live alone rather than with roommates), encourage migration from other regions, and/or lead to more ownership of vacation homes or pieds-à-terre.

ITE's recommended practice in the Trip Generation Handbook partially recognizes issues of scale and (implicitly) the difference between average and marginal rates. It states (ITE 2004, p. 29, emphasis in original): "There are instances... when the total number of trips generated by a site is different from the amount of new traffic added to the street system by the generator." The handbook goes on to separate trips into three categories: primary trips, pass-by trips (intermediate destinations, where the driver simply stops along the way), and diverted linked trips (similar to pass-by trips but involving a diversion).

Pass-by and diverted linked trips represent new trips at the driveway or site-access level but not on the adjacent streets. "Overall, diverted linked trips represent a change in local area travel but constitute no new increase on a macroscopic scale," according to the handbook (ITE 2004, p. 33, emphasis in original). "Within the immediate study area, diverted linked trips do represent additional traffic on individual streets and should be analyzed that way." Thus, at the macroscopic scale, ITE's guidance would seem to equate marginal trips to primary trips and average trips to the sum of the three categories.

This framework, however, only partially captures the substitution effects that cause the average rate to exceed the marginal rate, because even primary trips do not necessarily increase travel at the macroscopic scale. A primary trip to a new grocery store may substitute for a primary trip to the household's previous store of choice. Moreover, pass-by trips and diverted linked trips might still increase total traffic levels. Consider, for example, the case where an individual chooses not to carpool because she needs to make an intermediate stop in order to have dinner at a restaurant. In other cases, pass-by trips and diverted linked trips might reduce traffic levels - for example, if a new grocery store allows an individual to stop and shop on his way to school rather than making a dedicated trip on another occasion.

In practice, issues of scale and the difference between marginal and average trip rates are ignored by analysts, with the possible exception of accounting for pass-by and diverted linked trips. The same trip generation rates are employed to determine the level of service at intersections adjacent to a development, the "fair share" contribution of a new development to freeway capacity improvements, and its impacts on regional air quality and global greenhouse gas emissions. In the first case of local intersections, it might be justifiable to disregard the distinction between average and marginal trips. In the second case of regional freeways, it seems dubious to ignore substitution effects that will affect freeway traffic volumes, and adjusting for pass-by and diverted linked trips will give an incomplete picture. In the third case of greenhouse gas emissions, the substitution component will be almost completely dominant, and standard trip generation rates are virtually irrelevant. Almost all trips will be substituted from other origins and destinations, and marginal trips will be effectively zero. While regional travel models are used for some greenhouse gas analyses, ITE trip generation rates usually provide the basis for estimating the climate change impacts of individual projects during the environmental review process. In a context of flat or even declining levels of vehicle travel (Puentes and Tomer 2008; Millard-Ball and Schipper 2011), new development does not "generate" trips—or greenhouse gas emissions—at the national scale, but simply reshuffles existing ones around. 


\section{Conclusion}

ITE's Trip Generation Manual and associated Trip Generation Handbook represent the standard practice when analyzing the traffic and environmental impacts of new development. With the exception of Shoup (1999, 2003), who focuses on issues of statistical precision and choice of explanatory variables, most criticism has focused on the inapplicability of ITE trip generation rates to mixed-use and transitoriented development. This paper suggests that the problems with ITE trip generation rates run far deeper and apply to development in general—not simply projects that generate less traffic by virtue of their density, mix of uses, or transit access.

I identify two core issues with the use of the trip generation rates published by ITE. First, the rates appear to greatly overestimate the total number of vehicle trips that can be attributed to any development project. Engineers and planners who use ITE rates are likely designing streets to cater for "phantom trips" that will never materialize. It is difficult to identify the precise reason for the discrepancy, but the self-selection of atypical projects into the ITE database may be an important cause.

Second, ITE-published trip generation rates must be interpreted as the average rate, not the marginal rate, and the marginal rate depends on the scale of the analysis. This is largely a criticism of standard practices in traffic engineering and air quality analysis rather than the quality of ITE's data. At the level of driveway accesses to a particular development, it makes sense to use an approach that is based on ITE trip generation rates since the average will be the same as the marginal. As the scale of the analysis expands to include arterials and freeways, substitution effects must be considered. When analyzing global greenhouse gas emissions, it is theoretically incoherent to base an analysis on average trip generation rates, as almost all of these "generated" trips will actually be substituted from other origins and destinations. Of course, most traffic studies focus on local traffic impacts (although even at intersections around a new development, some substitution may take place). However, ITE trip generation data are often used to assess transportation impact fees that fund city- or region-wide infrastructure, and for environmental analyses of air pollution or climate change impacts. Here, the distinction between marginal and average rates is critical.

It is the marginal number of trips that determines impacts on total vehicle travel and emissions, but the marginal number at the macroscopic scale cannot be determined from the data published by ITE. Rather, the number of marginal trips "generated" by a new development depends fundamentally on how individuals adjust their residential location and travel behavior to account for new housing choices and new destinations.

Indeed, at scales beyond the immediate vicinity of a particular development, it makes little sense to think of "trip generation"- the term is an impediment to understanding the causal processes at work. "Generation" implies that development causes trips to change in a mechanistic way-a certain square footage of retail or a certain number of residential units causes trips to increase. And causal language infuses ITE's (2004) Trip Generation Handbook. But when the marginal number of trips is of interest, the development's size may have less of an impact than its other characteristics.

Take, for example, the construction of a new courthouse. Presumably, the number of murders, divorces, and other legal matters - and thus the total number of trips to court-is not related to the square footage of court facilities in any causal way. Courts do not cause crime. Nevertheless, the new courthouse will cause trips to be relocated from other facilities, and its location, transit access and parking cost will influence the marginal number of trips. If the courthouse is located in a more transit-rich, denser center than before, the marginal impact may well be negative. For an even more extreme example, take a light-rail transit station with parking, which the Trip Generation Manual suggests will generate 2.51 trips per parking space per weekday. Perhaps this is true at the most local scale, but overall, the light-rail 
system is presumably intended to reduce vehicle trips.

What, then, is the practicing planner or engineer to do? Regional travel demand models provide an option for larger projects, but their application is likely to be too costly for small- to medium-size developments. For analysis of traffic movements at intersections adjoining a new development- the bread and butter of traffic engineering practice-it would seem wise to bear in mind that ITE trip generation rates are likely to lead to large overestimates. A crude approach would simply divide an ITE-based estimate by the size of the overestimate by land use, as in Table 2. Preferably, however, the analyst would seek more valid sources of trip generation data that are tailored to the characteristics of a particular demand-indeed, as recommended by ITE. New guidance on trip generation at mixed-use developments (e.g., Handy et al. 2013) will help here, and regional travel survey data may provide a useful alternative. Indeed, metropolitan planning organizations such as the Atlanta Regional Commission often conduct their own travel surveys. While such household surveys may underestimate the number of trips and total VMT, the evidence in this paper suggests that the underestimate from surveys is much less than the overestimate from the types of driveway counts reported in the Trip Generation Manual.

An altogether different approach is needed for analysis of traffic or air quality at a scale beyond the immediate vicinity of a development project. Travel demand models are normally used to quantify the impacts of regional initiatives, comprehensive plans, and some large development projects. Still, for most individual development projects, analysts use trip generation rates to quantify their wider traffic and environmental impacts - for example, when assessing development impact fees for both local and regional roadway improvements or when quantifying greenhouse gas emissions. Instead of conceptualizing new developments as generating traffic, it seems more useful to judge them against the baseline of existing development.

In a sprawling metropolitan region, high-density, transit-oriented housing will probably reduce total vehicle travel at the regional level, compared to the counterfactual where that housing was not built or was built in a more sprawling location. Granting reductions in trip generation for the transit-oriented nature of that housing is certainly a step in the right direction, but fundamentally it is misleading to think that such transit-oriented housing generates any trips at all at a regional scale. A more reasonable starting point is to consider that new development is just as likely to reduce traffic, air pollution, and greenhouse gas emissions as it is to increase them. The seemingly benign, technocratic nature of traffic analysis in practice works against policies designed to reduce vehicle travel.

As of the time of writing, traffic levels at the national level in the United States have flattened out, while development is rebounding following the economic downturn. When considered together, these two trends are incompatible with the idea that new development generates traffic at any scale beyond the local. But current practices in planning and traffic engineering demand that roadway infrastructure be designed, and developers assessed fees, to cater for both actual and phantom trips. Rethinking the assumptions behind trip generation studies may not only help avoid wasting resources on oversized roadways and intersections, but also support efforts to promote transit-oriented, livable communities.

\section{Acknowledgments}

I appreciate helpful comments and suggestions on earlier drafts from Donald Shoup and the Access team at UCLA, Jerry Walters, Brian Canepa, Rachel Weinberger, Mark Massoud, and anonymous reviewers. 


\section{References}

Barnard, P. O., and R. E. Brindle. 1987. A review and critique of current methods used to predict traffic generation with some accompanying suggestions on alternative approaches. Transportation Planning and Technology 11(4): 273-288. doi: 10.1080/03081068708717349.

Bochner, B. S., K. Hooper, B. Sperry, and R. Dunphy. 2011. Enhancing Internal Trip Capture Estimation for Mixed-Use Developments. NCHRP Report 684. Washington, DC. http://www.trb.org/Main/Blurbs/165014.aspx.

Bricka, S. G., S. Sen, R. Paleti, and C. R. Bhat . 2012. An analysis of the factors influencing differences in survey-reported and GPS-recorded trips. Transportation Research Part C: Emerging Technologies 21(1): 67-88. doi: 10.1016/j.trc.2011.09.005.

Bricka, S. G., and C. R. Bhat. 2006. Comparative analysis of global positioning system-based and travel survey-based data. Transportation Research Record 1972: 9-20. http://trid.trb.org/view/2006/C/776348.

Byrne, B., M. Carr, and J. Sumner. 2012. Preparation of the Vermont Trip Generation Manual. ITE Journal 82(6): 42-47.

California Air Pollution Control Officers Association (CAPCOA). 2008. CEQA and Climate Change. Evaluating and Addressing Greenhouse Gas Emissions from Projects Subject to the California Environmental Quality Act. Sacramento. http://www.capcoa.org/wp-content/uploads/2012/03/CAPCOA-White-Paper.pdf.

CAPCOA. 2010. Quantifying Greenhouse Gas Mitigation Measures. A Resource for Local Government to Assess Emission Reductions from Greenhouse Gas Mitigation Measures. Sacramento. http://capcoa.org/wp-content/uploads/2010/11/CAPCOA-Quantification-Report-9-14-Final.pdf.

Cervero, R., and G. B. Arrington. 2008. Vehicle trip reduction impacts of transit-oriented housing. Journal of Public Transportation 11(3): 1-17. http://www.nctr.usf.edu/jpt/pdf/JPT11-3Cervero.pdf.

Clifton, K. J., K. M. Currans, and C. D. Muhs. 2012. Contextual Influences on Trip Generation. Portland, OR.

Ewing, R., Greenwald, M., Zhang, M., Walters, J., Feldman, M., Cervero, R., Frank, L., and Thomas, J. 2011. Traffic generated by mixed-use developments: six-region study using consistent built environmental measures. Journal of Urban Planning and Development 137(3): 248-261. doi: 10.1061/ (ASCE)UP.1943-5444.0000068.

Ewing, R., R. Pendall, and D. Chen. 2002. Measuring Sprawl and its Impact. Washington, DC.

FHWA. 1985. Development and Application of Trip Generation Rates, Washington, DC.

FHWA. 2011a. 2009 National Household Travel Survey. Version 2.1. http://nhts.ornl.gov.

FHWA. 2011b. Highway Statistics 2010, Washington, DC.

FHWA. 2011c. Summary of Travel Trends: 2009 National Household Travel Survey. Washington, DC.

Handy, S., K. Shafizadeh, and R. Schneider. 2013. California Smart-Growth Trip Generation Rates Study Draft Report. Davis, CA.

Institute of Transportation Engineers (ITE). 2004. Trip Generation Handbook. Second edition. Washington, DC: Institute of Transportation Engineers.

ITE. 2012. Trip Generation Manual. Ninth edition. Washington, DC: Institute of Transportation Engineers.

Lee, R., J. Miller, R. Maiss, M. M. Campbell, K. R. Shafizadeh, D. A. Niemeier, S. L. Handy, T. Parker. 2011. Evaluation of the Operation and Accuracy of Five Available Smart Growth Trip Generation Methodologies. Davis, CA. http://www.its.ucdavis.edu/?page_id=10063\&pub_id=1495.

Mannering, F. L., W. P. Kilareski, and S. S. Washburn. 2004. Principles of Highway Engineering and Traffic Analysis. Third edition. Hoboken, NJ: Wiley. 
Metz, D. 2010. Saturation of demand for daily travel. Transport Reviews 30(5): 659-674. doi: $10.1080 / 01441640903556361$.

Millard-Ball, A., and L. Schipper. 2011. Are we reaching peak travel? Trends in passenger transport in eight industrialized countries. Transport Reviews 31(3): 357-378. doi: 10.1080/01441647.2010.518291.

Millard-Ball, A., and P. Siegman. 2006. Playing the numbers game. Planning May 2006: 18-21.

Muldoon, D., and L. D. Bloomberg. 2008. Development of best practices for traffic impact studies. Transportation Research Record 2077: 32-38. doi: 10.3141/2077-05.

Pucher, J., R. Buehler, D. Merom, and A. Bauman. 2011. Walking and cycling in the United States, 2001-2009: Evidence from the National Household Travel Surveys. American Journal of Public Health 101(S1): S310-S317. doi: 10.2105/AJPH.2010.300067.

Puentes, R., and A. Tomer. 2008. The Road... Less Traveled: An Analysis of Vehicle Miles Traveled Trends in the U.S. Washington, DC: Brookings Institution.

Reid, F. A. 1982. Critique of ITE trip generation rates and an alternative basis for estimating new area traffic. Transportation Research Record 874: 1-5.

San Diego Association of Governments (SANDAG). 2002. Brief Guide of Vehicular Traffic Generation Rates for the San Diego Region. San Diego. http://www.sandag.org/uploads/publicationid/publicationid_1140_5044.pdf.

Shoup, D. C. 1999. The trouble with minimum parking requirements. Transportation Research Part A: Policy and Practice 33(7-8): 549-574. doi: 10.1016/S0965-8564(99)00007-5.

Shoup, D. C. 2003. Truth in transportation planning. Journal of Transportation and Statistics 6(1): 1-16. US Department of Energy. 2012. 2011 Buildings Energy Data Book. Washington, DC: US Department of Energy.

Walters, G., R. Ewing, and W. Schroeer. 2000. Adjusting computer modeling tools to capture effects of smart growth: Or "poking at the project like a lab rat." Transportation Research Record 1722: 17-26. doi: 10.3141/1722-03.

Wolf, J., M. Oliveira, and M. Thompson. 2003. Impact of underreporting on mileage and travel time estimates: results from global positioning system-enhanced household travel survey. Transportation Research Record 1854: 189-198. doi: 10.3141/1854-21. 